\title{
Corrigendum to "Osteoporosis Recovery by Antrodia camphorata Alcohol Extracts through Bone Regeneration in SAMP8 Mice"
}

\author{
Hen-Yu Liu, ${ }^{1,2}$ Chiung-Fang Huang, ${ }^{3}$ Chun-Hao Li, ${ }^{1,4}$ Ching-Yu Tsai, ${ }^{1,4}$ \\ Wei-Hong Chen, ${ }^{1,4}$ Hong-Jian Wei, ${ }^{1,4}$ Ming-Fu Wang, ${ }^{5}$ Yueh-Hsiung Kuo, ${ }^{6,7}$ \\ Mei-Leng Cheong, ${ }^{8,9}$ and Win-Ping Deng ${ }^{1,4,10}$ \\ ${ }^{1}$ Stem Cell Research Center, Taipei Medical University, Taipei 110, Taiwan \\ ${ }^{2}$ School of Dentistry, College of Oral Medicine, Taipei Medical University, Taipei 110, Taiwan \\ ${ }^{3}$ Department of Dentistry, Taipei Medical University Hospital, Taipei 110, Taiwan \\ ${ }^{4}$ Graduate Institute of Biomedical Materials and Tissue Engineering, Taipei Medical University, Taipei 110, Taiwan \\ ${ }^{5}$ Department of Food and Nutrition, Providence University, Taichung 433, Taiwan \\ ${ }^{6}$ Department of Chinese Pharmaceutical Sciences and Chinese Medicine Resources, China Medical University, Taichung 404, Taiwan \\ ${ }^{7}$ Department of Biotechnology, Asia University, Taichung 413, Taiwan \\ ${ }^{8}$ Department of Obstetrics and Gynecology, Cathay General Hospital, Taipei 106, Taiwan \\ ${ }^{9}$ Department of Obstetrics and Gynecology, School of Medicine, College of Medicine, Taipei Medical University, Taipei 110, Taiwan \\ ${ }^{10}$ Institute of Medicine, Fu Jen Catholic University, Taipei 242, Taiwan
}

Correspondence should be addressed to Mei-Leng Cheong; joymlcheong@gmail.com and Win-Ping Deng; wpdeng@tmu.edu.tw

Received 2 January 2017; Accepted 16 January 2017; Published 15 February 2017

Copyright (c) 2017 Hen-Yu Liu et al. This is an open access article distributed under the Creative Commons Attribution License, which permits unrestricted use, distribution, and reproduction in any medium, provided the original work is properly cited.

In the article titled "Osteoporosis Recovery by Antrodia camphorata Alcohol Extracts through Bone Regeneration in SAMP8 Mice" [1], affiliation number nine was incomplete. The corrected affiliation is shown above.

\section{References}

[1] H.-Y. Liu, C.-F. Huang, C.-H. Li et al., "Osteoporosis recovery by Antrodia camphorata alcohol extracts through bone regeneration in SAMP8 mice," Evidence-Based Complementary and Alternative Medicine, vol. 2016, Article ID 2617868, 9 pages, 2016. 


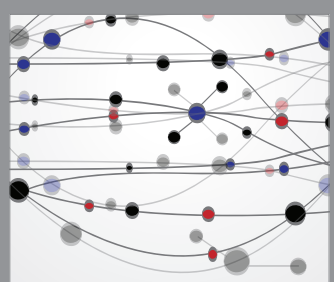

The Scientific World Journal
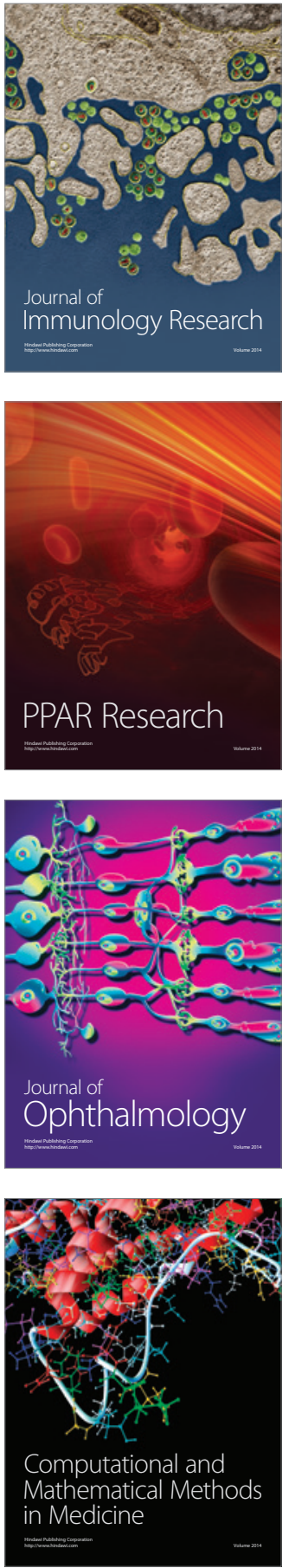

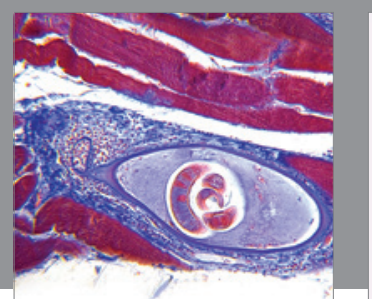

Gastroenterology Research and Practice
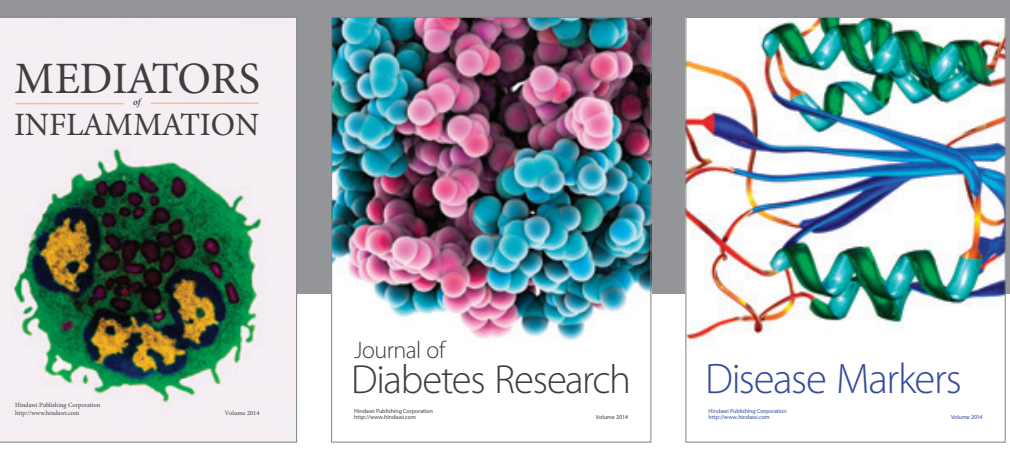

Disease Markers

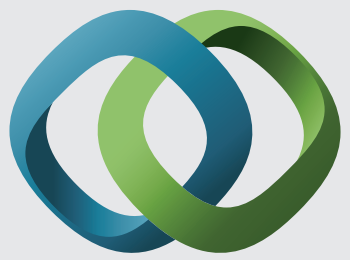

\section{Hindawi}

Submit your manuscripts at

https://www.hindawi.com
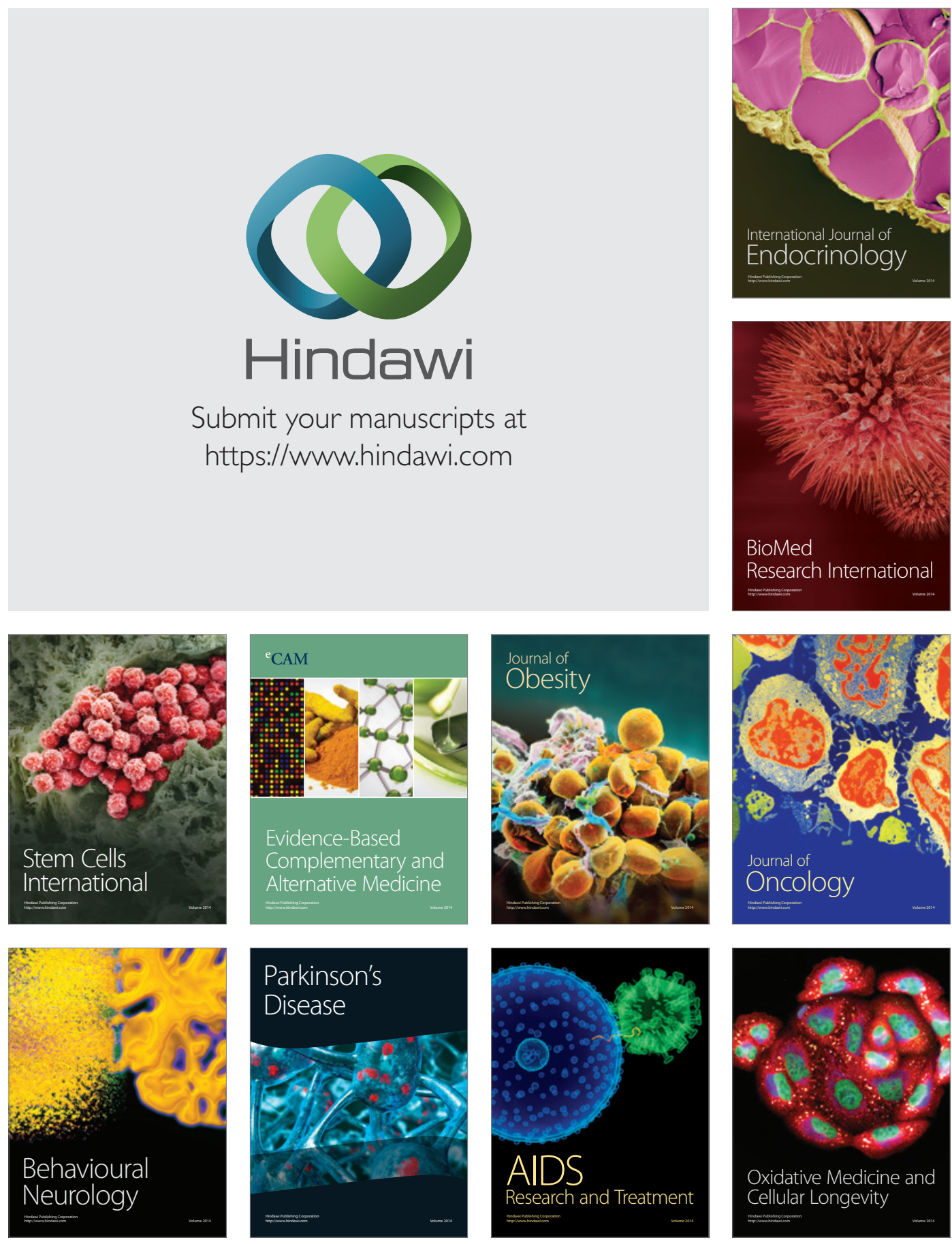